\title{
Lutas feministas nos documentos do Conselho Federal de Serviço Social (CFESS): uma breve análise
}

\author{
Feminist struggles in the documents of the \\ Federal Council of Social Work: a concise analysis
}

\author{
Luciana Ribeiro Paneghini \\ Assistente social do Ministério Público de São Paulo. Graduada pela Fapss São Caetano do Sul e \\ mestre em Serviço Social pela PUC-SP, São Paulo, Brasil. lucianaservicosocial@gmail.com
}

Resumo: Este artigo apresenta os posicionamentos do CFESS sobre temas feministas, emitidos nos últimos dez anos. Por meio da pesquisa de suas resoluções e manifestos, observou-se que o CFESS debate tais questões dentro de uma perspectiva anticapitalista, anti-homofóbica e antirracista, com o fito de construir diretrizes para o exercício profissional, enquanto entidade máxima de representação do Serviço Social.

Palavras-chave: Feminismo. Serviço Social. Posicionamento.
Abstract: This article presents the positions of CFESS on feminist issues, issued in the last ten years. Through the research of its resolutions and manifests, it was observed that the CFESS discusses such issues within ananti-capitalist and anti-racist perspective, with the purpose of constructing guidelines for the professional exercise, as the maximum representative entity of Social Work.

Keywords: Feminism. Social Work. Positioning.

\section{Introdução}

os tempos atuais, há um clamor feminista que ecoa na sociedade. O feminismo difuso ${ }^{1}$ do século XXI é de extrema relevância para publicizar e enfrentar as relações desiguais de gênero, tanto

1. Nos dizeres de Pinto (2003), o feminismo difuso refere-se a um discurso feminista e um rechaço ao machismo que estão pulverizados na fala de homens e mulheres, não necessariamente militantes de movimentos 
as de âmbito doméstico e intrafamiliar, como aquelas que se perpetuam no espaço público. Estamos vivendo um momento de extrema relevância para o fortalecimento do protagonismo das mulheres e dos segmentos transgressores da heteronormatividade, em todos os aspectos da vida. E o discurso feminista permeia diversos espaços na mídia, seja nas novelas e programas de auditório, seja nas redes sociais dos(as) famosos(as) ou de pessoas comuns.

Ressalta-se que tais lutas não estão restritas à mídia ou às redes sociais. No âmbito da mobilização social, as mulheres têm lutado muito nas ruas contra as diversas expressões da violência de gênero. No caso da América do Sul, destaca-se o movimento Ni Una Menos, que tem levado adiante manifestações contra os feminicídios e a violência sexual. No Brasil, em 2015, a Primavera das Mulheres tomou conta das ruas, combatendo o aparelhamento religioso do Estado e as propostas advindas dos setores mais fundamentalistas e conservadores do Congresso, que intentavam, dentre outras medidas, o cerceamento do direito das mulheres ao aborto, nos casos em que já é legalizado.

Sabe-se, no entanto, que há diversas matizes de feminismo e há, ainda, diversos fins para os quais as lutas desse movimento se destinam. Enquanto as feministas liberais lutam por direitos iguais por dentro do sistema capitalista, as feministas socialistas lutam lado a lado com elas pelos mesmos direitos, porém mirando a construção de uma sociedade sem classes e sem opressão, junto à classe trabalhadora de conjunto. No interior do feminismo, em geral tem-se fomentado discussões sobre as especificidades do "ser mulher". Ou seja, felizmente, há um reforço da reflexão feminista em torno da questão étnico-racial e das identidades de gênero e orientações sexuais divergentes da heterossexualidade compulsória, o que fortalece sobremaneira o movimento e ainda mais aqueles que se estabelecem dentro do universo anticapitalista, já que este sistema explora de formas diferenciadas os(as) trabalhadores(as),

feministas. O feminismo difuso, com certeza, é produto da luta das feministas que, apesar de todos os entraves, conseguiram pautar suas demandas nos debates políticos e na sociedade. 
de acordo com as especificidades de suas opressões, vivenciadas em torno de suas identidades.

E o Serviço Social, como tem se colocado diante deste debate? O presente artigo busca responder a esta questão, por meio da pesquisa de resoluções e manifestos do CFESS presentes em seu site oficial. Para contextualizar este tema, o primeiro segmento deste trabalho busca apresentar um breve histórico sobre o processo de ruptura com o conservadorismo, o qual contribuiu para que a entidade máxima da profissão expresse os posicionamentos emitidos atualmente. No segundo tópico há uma explanação sobre as resoluções que tratam de temas feministas de combate à desigualdade de gênero e à LGBTfobia. E, no terceiro, serão analisados os CFESS Manifesta, manifestos que expressam a opinião do Conselho sobre temas diversos, pertinentes aos públicos atendidos pelo Serviço Social. Ao final, breves considerações fecham este trabalho, mas não a discussão.

\section{Processo histórico de ruptura do Serviço Social com o conservadorismo}

O Serviço Social brasileiro, nos anos 1970 e 1980, empreendeu um processo de autorreflexão e revisão de seu conteúdo ético e metodológico, também reconhecido como processo de reconceituação da profissão.

De acordo com Netto (2011), o processo de reconceituação do Serviço Social não se demonstrou coeso no interior da categoria profissional: havia grupos de profissionais que intentavam uma revisão técnica da profissão dentro dos marcos da ditadura; outros mais conservadores, vinculados à Igreja Católica, que não desejavam alterar as bases e as práticas profissionais; e o outro grupo, que visava romper com o conservadorismo. Este último foi o que mais influenciou o Serviço Social atual e suas entidades representativas.

O grupo que intentava romper com as práticas conservadoras, nesse período, passou a revisar também as bases teóricas da profissão por meio da leitura de autores(as) que explicavam, a partir de um ponto de vista 
anticapitalista, as razões da pobreza e do descaso dos governantes para com os(as) pobres, a existência das instituições burguesas, entre outras matérias. A partir de então, esse grupo de profissionais começa a se aproximar da teoria marxista, ainda que em um primeiro momento de maneira indireta e eclética.

Posteriormente, tais profissionais buscaram compreender as próprias obras marxianas e os(as) autores(as) marxistas, sobretudo Antonio Gramsci, Agner Heller e Gyorg Lukács, entre outros(as), o que contribuiu para o amadurecimento teórico e metodológico da apreensão de temas como ética e de conceitos como liberdade, justiça social, democracia etc. Tal amadurecimento, percebido no âmbito acadêmico, se espraiou para a categoria profissional e suas entidades representativas, sobretudo por meio da produção teórica e da participação dos(as) profissionais progressistas nas instituições do Serviço Social, enquanto profissão.

Contudo, não foi apenas o marxismo apreendido na academia que propiciou uma visão mais crítica da sociedade e da própria profissão aos(às) assistentes sociais: de maneira dialética, isso se deu através da aproximação dos profissionais em relação à população usuária e aos movimentos sociais, seja aqueles que buscavam a democratização da sociedade (movimento contra a ditadura militar, pela anistia etc.), seja aqueles relacionados às lutas contra as opressões vivenciadas por segmentos específicos.

À época, muitas assistentes sociais já militavam em partidos de esquerda, compunham as entidades sindicais da própria profissão ${ }^{2}$ e participavam de movimentos de mulheres ou feministas. ${ }^{3}$ De acordo com Paneghini (2016), as

2. Cite-se a Ceneas (Comissão Executiva Nacional de Entidades Sindicais de Assistentes Sociais), que esteve ativa entre 1979 e 1983, e a Anas (Associação Nacional dos Assistentes Sociais), a qual deu continuidade à Ceneas e organizou os sindicatos da categoria de 1983 a 1992. De acordo com Abramides e Cabral (2009), a organização sindical dos(as) assistentes sociais tomou novos rumos, desde a extinção da Anas, em 1992, devido à deliberação da IV Assembleia Sindical Nacional, que aconteceu em Campinas, em 1989, a qual determinou a inserção dos(as) assistentes sociais em organismos sindicais agrupados por ramo de atividade, e não mais por categoria profissional. É relevante mencionar, ainda, a importância da existência da Apassp (Associação Profissional dos Assistentes Sociais do Estado de São Paulo), entidade pré-sindical das(os) assistentes sociais, ativa nos anos 1970 e 1980.

3. Segundo Teles (1999), o movimento de mulheres é o agrupamento que as organiza politicamente para reivindicar melhores condições de vida e/ou de trabalho. Já o movimento feminista denuncia a sociedade 
assistentes sociais se aproximaram das demandas do feminismo a partir das necessidades concretas das mulheres trabalhadoras, que as levavam a reivindicar melhores condições de vida em seus bairros, sindicatos, universidades e empregos. Portanto, o Serviço Social entrou em contato com a luta feminista por meio, sobretudo, dos enfrentamentos das mulheres trabalhadoras contra a carestia de vida e por melhorias em sua comunidade, nos Clubes de Mães, através dos movimentos por creche, habitação etc.

Sob essa compreensão marxista e libertária sobre a sociedade capitalista, o então denominado CFAS (Conselho Federal de Assistência Social) e depois o seu substituto, CFESS, ${ }^{4}$ puderam repensar o projeto ético-político da profissão e, assim, dar vida aos Códigos de Ética Profissional de 1986 e de 1993, os quais reconhecem a necessidade da construção de uma ordem societária justa e igualitária, a qual não poderá realizar-se nos marcos do capitalismo.

O Código mais atual, Resolução CFESS n. 273/93, foi construído para suprir insuficiências presentes no Código de 1986. Nele há expresso "reconhecimento da liberdade como valor ético central e das demandas políticas a ela inerentes - autonomia, emancipação e plena expansão dos indivíduos sociais" (CFESS, 1993). A emancipação, por sua vez, é o valor de natureza humano-genérica fundamental, na medida em que "os demais princípios (valores) essenciais: a liberdade, a justiça social, a equidade e a democracia são simultaneamente valores e formas de viabilização da emancipação humana" (Barroco e Terra, 2012, p. 58).

Ou seja, o Código orienta que os(as) assistentes sociais, em seu trabalho profissional, devem pautar a sua atuação no reconhecimento da liberdade

\footnotetext{
machista, combatendo a discriminação e a subalternidade das mulheres na sociedade patriarcal. Aqui serão utilizados os dois conceitos, embora muito frequentemente os movimentos de mulheres fundamentem as suas lutas a partir de reflexões feministas e os movimentos feministas lutem pelas demandas abarcadas pelos movimentos de mulheres, a partir de sua crítica ao patriarcado.

4. O CFAS se tornou CFESS em 1993, por meio da alteração de nomenclatura do Conselho preconizada na Lei de Regulamentação da Profissão, Lei n. 8.662 de 7 de junho de 1993. A mesma normativa também mudou o nome dos Cras (Conselhos Regionais de Assistentes Sociais) para Cress (Conselhos Regionais de Serviço Social).
} 
dos sujeitos atendidos, impulsionando ou ao menos não restringindo a sua autodeterminação, enquanto sujeitos ético-políticos. O valor da liberdade inserido como princípio fundamental é de extrema relevância para a normatização ética da profissão e para a própria construção do nosso projeto ético e político, uma vez que ele pretende direcionar a atuação profissional ao combate às práticas reiterativas da tutela e do cerceamento dos comportamentos, tão características das intervenções conservadoras.

Outros princípios do Código de Ética que se referem diretamente ao tema deste artigo dizem respeito ao empenho na luta pela eliminação de qualquer forma de discriminação, incentivando o respeito à diversidade e a participação dos segmentos socialmente discriminados; à busca pela construção de uma nova ordem social, sem exploração de classe, gênero ou etnia; à articulação com movimentos sociais que tenham afinidade com os princípios do Código; à defesa do exercício profissional sem ser discriminado(a) por raça, gênero, "opção" 5 sexual, opção religiosa, classe social, condição física e idade.

\section{Documentos do CFESS que explicitam o combate ao machismo e à heteronormatividade}

Além de o Código de Ética de 1993 evocar princípios que valorizam a liberdade e a autodeterminação dos sujeitos éticos e preconizam a defesa intransigente dos direitos humanos, o CFESS produziu três resoluções que dizem respeito ao combate à desigualdade de gênero e à discriminação da população LGBT.

No ano de 2006, o CFESS lançou a Resolução n. 489/2006, que "estabelece normas vedando condutas discriminatórias ou preconceituosas, por orientação e expressão sexual por pessoas do mesmo sexo, no exercício

5. O termo "opção sexual" presente no Código de Ética de 1993 foi alterado para "orientação sexual", conforme a Resolução n. 594/2011, como será mais bem explanado a seguir. 
profissional do assistente social, regulamentando princípio inscrito no Código de Ética Profissional" (CFESS, 2006, p. 1).

A referida resolução está em consonância com a instituição da Campanha Nacional pela Liberdade de Orientação e Expressão Sexual — “O amor fala todas as línguas: assistentes sociais na luta contra o preconceito” —, aprovada no XXXIV Encontro Nacional CFESS/Cress. Além disso, a resolução faz uma crítica à abordagem liberal-burguesa sobre o tema dos direitos humanos, reconhecendo a necessidade de estimular a reflexão sobre o sentido da liberdade e a necessidade histórica de os indivíduos escolherem por sua sexualidade e afetividade.

No CFESS Manifesta, publicado na ocasião da referida campanha, o Conselho informa o seguinte:

Pensar, portanto, essa campanha no âmbito do projeto ético-político-profissional nos remete ao entendimento de que as profissões não atualizam suas agendas de forma linear, como mera evolução no tempo. Ao contrário disso, as mudanças no âmbito do Serviço Social são produto das determinações sócio-históricas e de um processo coletivo, revelado no esforço teórico-ético-político para sintonizar nossa profissão com demandas e questões que possibilitem apreender o exercício profissional antenado com um projeto de sociedade radicalmente crítico à sociabilidade do capital em seu movimento permanente de reprodução da desigualdade e de naturalização de múltiplas formas de opressão e exploração. (CFESS, 2007, p. 1)

Assim, a campanha não só teve o objetivo de mobilizar a categoria quanto ao tema, combatendo a homofobia no âmbito do trabalho profissional com a população usuária, como demonstrou estar em sintonia com um projeto societário mais abrangente, produto do debate social estimulado nos processos coletivos de mobilização contra a homofobia e a heteronormatividade. Vale ressaltar que essa campanha levada adiante pelo CFESS foi realizada em parceria com os movimentos Divas (Instituto em Defesa da Diversidade Afetivo-Sexual); LBL (Liga Brasileira de Lésbicas); ABL 
(Articulação Brasileira de Lésbicas) e ABGLT (Associação Brasileira de Gays, Lésbicas, Bissexuais, Travestis e Transexuais).

Em 2011, o CFESS lançou duas resoluções sobre os temas aqui analisados: a Resolução n. 594, de 21 de janeiro, e a Resolução n. 615, de 8 de setembro. A primeira altera alguns aspectos do Código de Ética, incorporando a linguagem de gênero ao texto original, a partir da adoção das formas feminina e masculina (o/a; os/as) para designar usuários(as), trabalhadores(as), dentre outros(as), e da substituição da nomenclatura "opção sexual”, contida no Código de Ética de 1993, por “orientação sexual”, em consonância com a linguagem utilizada pelo movimento LGBT. Em seus "considerandos", a mencionada normativa reitera

a necessidade de garantir a linguagem de gênero, incluindo nos textos do Código de Ética a menção de "ambos os gêneros", conforme procedimento que vem sendo adotado em todos os textos e publicações do CFESS, de forma a contribuir com uma atitude de desconstrução do machismo na linguagem gramatical; considerando, ainda, a supremacia da categoria dos assistentes sociais representada, nacionalmente por mais de 95\% de mulheres [...]. (CFESS, 2011a, p. 1)

Já a Resolução n. 615, de 8 de setembro de 2011, “dispõe sobre a inclusão e uso do nome social da assistente social travesti e do(a) assistente social transexual nos documentos de identidade profissional" (CFESS, 2011b, p. 1). O documento aponta em seus "considerandos" diversos aspectos feministas e libertários, além de trazer elementos que expõem a necessária construção de uma sociedade sem classes, como segue:

[...] é objetivo do CFESS a construção de uma sociedade radicalmente justa e democrática sem preconceitos de origem, raça, etnia, sexo, orientação sexual, identidade de gênero, cor, idade ou quaisquer outras formas de discriminação, em consonância com o Código de Ética do(a) Assistente Social; [...] os direitos à livre orientação sexual e à livre identidade de gênero constituem direitos humanos de lésbicas, gays, bissexuais, travestis e transexuais (LGBT), e que a sua proteção requer ações efetivas das entidades do Serviço Social no sentido de assegurar o pleno exercício da cidadania da população LGBT (lésbicas, gays, 
bissexuais, travestis e transexuais); [...] toda pessoa tem direito ao tratamento correspondente a sua identidade de gênero; [...] se define identidade de gênero como a "experiência interna e individual do gênero de cada pessoa, que pode ou não corresponder ao sexo atribuído no nascimento, incluindo o senso pessoal do corpo (que pode envolver, por livre escolha, modificação da aparência ou função corporal por meios médicos, cirúrgicos ou outros) e outras expressões de gênero, inclusive vestimenta, modo de falar e maneirismos" (Princípios de Yogyakarta, 2006). [...] a presente Resolução traduz os pressupostos do Projeto Ético e Político do Serviço Social que contém a projeção de uma outra sociabilidade - "aquela em que se propicie aos trabalhadores um pleno desenvolvimento para a invenção e vivência de novos valores, o que, evidentemente, supõe a erradicação de todos os processos de exploração, opressão e alienação". (CFESS, Código de Ética do(a) Assistente Social, 2011). (CFESS, 2011b, p. 1)

A partir dessa resolução, as(os) assistentes sociais travestis e/ou transexuais puderam requerer a inscrição de seu nome social na cédula e na carteira de identidade profissional, bem como nos procedimentos e atos do conjunto CFESS/Cress.

O documento é uma das expressões mais claras de que a entidade tem se atentado para a luta LGBT e feminista pelo reconhecimento da identidade de gênero de homens e mulheres, independentemente de seu sexo biológico, reafirmando os princípios do Código de Ética profissional, na luta contra todas as formas de discriminação e na afirmação da diversidade humana, caminhando na contracorrente da moral conservadora.

Vale citar que, em 2016, o CFESS elaborou uma série de cadernos denominada Assistente Social no combate ao preconceito, sendo o caderno de número 4 destinado ao tema da transfobia.

\subsection{Posicionamentos feministas nos CFESS Manifesta}

Além das resoluções citadas, foram analisados os conteúdos dos CFESS Manifesta, documentos políticos em que o Conselho Federal da 
categoria se posiciona sobre determinado assunto de interesse dos(as) usuários(as) dos serviços em que as(os) assistentes sociais atuam. Para tanto, realizou-se pesquisa no site da entidade dos documentos cujos títulos enunciados tratassem de temas como o combate à violência contra a mulher; combate à homofobia, lesbofobia e transfobia; combate à exploração sexual de mulheres e crianças, legalização e descriminalização do aborto, dentre outros temas de interesse dos movimentos feministas e de mulheres. A pesquisa apurou manifestos emitidos entre abril de 2007 e dezembro de 2017, sendo constatada a publicação de 32 documentos divididos entre os seguintes assuntos:

Figura 1 - Incidência de temas feministas dos CFESS Manifesta (2007-17)

\begin{tabular}{|l|c|}
\hline LGBT (geral)* & 6 \\
\hline Combate à violência contra a mulher e contra crianças e adolescentes** & 6 \\
\hline Dia Internacional da Mulher & 7 \\
\hline Lei Maria da Penha e políticas para mulheres & 3 \\
\hline Legalização e descriminalização do aborto & 4 \\
\hline Visibilidade lésbica & 3 \\
\hline Visibilidade trans & 2 \\
\hline Trabalho doméstico remunerado & 1 \\
\hline Total & $\mathbf{3 2}$ \\
\hline
\end{tabular}

Fonte: CFESS, 2017.

* Nesse item foram contabilizados manifestos diversos relacionados ao público LGBT em geral; as questões específicas acerca da visibilidade lésbica e trans foram contabilizadas separadamente.

** Neste quesito foram englobados temas como exploração sexual e tráfico de mulheres e crianças/ adolescentes, bem como o tema do combate à violência sexual contra crianças e adolescentes.

Nos manifestos analisados, pôde-se perceber que a maioria menciona o movimento feminista. Aqueles que não fazem menção direta, apresentam de maneira clara demandas femininas que dizem respeito às bandeiras de luta do feminismo. O movimento feminista socialista é mencionado em três manifestos, de maneira clara e direta. 
Alguns se remetem aos movimentos LGBT e negro, sobretudo quando se referem aos dias de luta LGBT ou da visibilidade lésbica. Nos manifestos que englobam esses temas, são mencionados não apenas os movimentos feministas lésbicos, mas os marcos históricos em que as lutas contra a lesbofobia se desenvolveram.

Em todos os manifestos há interface entre as dimensões de classe e de gênero, seja de maneira explícita (quando são mencionadas as condições de vida das mulheres trabalhadoras, por exemplo) ou de maneira mais velada, como é o caso da menção à luta contra toda forma de exploração e opressão, com vistas à construção de uma sociedade em que a emancipação humana seja integralmente possível. Muitos manifestos citam o combate ao capitalismo patriarcal e/ou mencionam a articulação entre capitalismo, patriarcado e racismo, como sistemas de dominação/exploração que marcam a cultura e a sociabilidade brasileiras. Assim, vários manifestos mencionam as condições de vida às quais as mulheres negras estão expostas, evocando a luta contra 0 racismo e a mercantilização do corpo da mulher negra como um dos pontos de reivindicação do próprio movimento feminista de conjunto.

Nesse mesmo sentido, as péssimas condições de trabalho das trabalhadoras domésticas são analisadas no manifesto "Para romper a herança da escravidão" como produto da divisão sócio-sexual do trabalho, em que o trabalho doméstico é invisibilizado e visto historicamente como não trabalho, devido às heranças patriarcal e escravocrata, ainda tão presentes no Brasil. Tal afirmação aponta para o fato de que a categoria tem estado em sintonia com a luta das mulheres trabalhadoras, contra a precarização das relações de trabalho.

A interconexão dos temas profissão e movimentos (feministas, de mulheres, LGBT ou negro) aparece em alguns manifestos de forma explícita, como é o caso do CFESS Manifesta "Uma vida sem violência é um direito das mulheres: comprometa-se, tome uma atitude, exija seus direitos", publicado na ocasião da campanha dos dezesseis dias de ativismo pelo fim da violência contra as mulheres, coordenada pela Agende (Ações em Gênero, Cidadania e Desenvolvimento), a qual o CFESS não apenas 
apoiou, mas também integrou. Um dos trechos do referido manifesto chama as assistentes sociais para uma militância combativa em favor da vida das mulheres:

Atue individual e coletivamente na defesa da Lei Maria da Penha. Esta lei é resultado das lutas feministas e de vários sujeitos coletivos. Não podemos permitir retrocessos no enfrentamento às formas de violência contra a mulher. O CFESS orienta-se na defesa intransigente dos direitos humanos e na luta contra todas as formas de exploração e de opressão. As militantes feministas, assistentes sociais e demais profissionais que lutam para que a perspectiva de gênero, de raça/etnia e orientação sexual sejam incorporadas em todas as políticas públicas e em seu exercício profissional, fazem a diferença na construção cotidiana da história. (CFESS, 2009, p. 2)

Deve-se destacar também para dois manifestos em especial: um deles, “Assistentes sociais nos serviços de abortamento", de 2017, emite orientações éticas e técnicas para a atuação profissional dos(as) assistentes sociais junto a mulheres que sofreram ou provocaram aborto, com base na norma técnica Atenção humanizada ao abortamento; e o outro, Assistentes sociais contra a violência e por direitos de pessoas LGBT, publicado em 2015 por ocasião da realização do Seminário Nacional Serviço Social e Diversidade Trans: Exercício Profissional, Orientação Sexual e Identidade de Gênero em Debate. Ambos dão enfoque para o direcionamento ético à atuação profissional junto a esses segmentos, o que demonstra não apenas uma aproximação militante em relação aos temas, mas também reconhece os desafios engendrados por tais questões no cotidiano de trabalho dos(as) assistentes sociais.

\section{Considerações finais}

Conforme o exposto, a entidade máxima de representação da categoria, o CFESS, tem tratado de temas atinentes às lutas feministas mesmo antes de 
tais assuntos serem pautados com tanta facilidade pela mídia ou nas redes sociais. É o que se pode observar em seu site, objeto do estudo em questão e no qual constam todos os seus manifestos e resoluções a esse respeito e a outros temas relativos à defesa dos direitos humanos.

As resoluções citadas, emitidas após a construção do Código de Ética de 1993, aperfeiçoam o entendimento dos conceitos que se referem à luta contra a opressão de gênero, o que demonstra que a principal entidade do Serviço Social tem se atualizado para atender às demandas das mulheres e do segmento LGBT, fazendo-se presente nos movimentos sociais que combatem o machismo e a LGBTfobia.

Em seus manifestos, o CFESS tem reiterado a luta contra os preconceitos; tem denunciado a ausência de serviços públicos de saúde que ofereçam atendimento para homens e mulheres que queiram passar pelo processo transexualizador; tem apoiado, desde 2009, a descriminalização do aborto e, desde 2010, sua legalização, compondo ${ }^{6}$, inclusive, a Frente Nacional contra a Criminalização das Mulheres e pela Legalização do Aborto; tem combatido a perspectiva de maternidade compulsória e lutado para que o direito à maternidade seja garantido de forma plena, por meio da implantação de creches, serviços de contraturno escolar, serviços de saúde, lazer etc.; tem apoiado o direito à equidade salarial e de trabalho entre homens e mulheres e combatido os assédios moral e sexual, no ambiente de trabalho; tem combatido a violência e a exploração sexual de crianças e adolescentes, que têm violado os direitos humanos principalmente das meninas etc. $\mathrm{E}^{7}$, em todos eles, o CFESS elenca os princípios do Código

6. Nesse aspecto, cabe um comentário para esclarecer a diferença entre descriminalização e legalização: descriminalizar o aborto significa tirá-lo das legislações penais, não imputando pena à mulher que interrompe a gravidez. Já a legalização diz respeito a um conjunto de medidas mais amplas, que inclui a regulamentação da política para o abortamento seguro, bem como a implantação de serviços que o realizem de maneira qualificada, humanizada e gratuita e a inclusão no SUS de políticas relacionadas ao planejamento familiar e aos direitos sexuais e reprodutivos femininos, para que não seja necessária a prática do aborto.

7. De acordo com o CFESS Manifesta "Denunciar é proteger. Sou assistente social. Eu denuncio!", elaborado para o Dia Nacional de Combate à Violência Sexual Contra Crianças e Adolescentes, no ano de 2013, oito em cada dez vítimas eram meninas. 
de Ética, articulando-os com as bandeiras de luta dos movimentos LGBT, feminista e negro.

Recebido em 15/1/18 - Aprovado em 27/2/18

\section{Referências bibliográficas}

ABRAMIDES, Maria Beatriz; CABRAL, Maria do Socorro. A organização política do Serviço Social e o papel da Ceneas/Anas na virada do Serviço Social brasileiro. 30 anos do Congresso da Virada. Brasília, CFESS, p. 55-78, 2009.

BARROCO, Maria Lúcia; TERRA, Sylvia Helena. Código de ética do/a assistente social comentado: Conselho Federal de Serviço Social (CFESS). São Paulo: Cortez, 2012.

CONSELHO FEDERAL DE SERVIÇO SOCIAL. Resoluções e portarias CFESS. Disponível em: $<$ http://www.cfess.org.br/visualizar/menu/local/resolucoes-e-portariascfess $>$. Acesso em: 10 jan. 2018.

. CFESS Manifesta. Disponível em: <http://www.cfess.org.br/visualizar/ manifesta>. Acesso em: 10 jan. 2018.

. Resolução CFESS n. 273/93. Institui o Código de Ética Profissional dos Assistentes Sociais e dá outras providências. Disponível em: $<\mathrm{http}: / /$ www.cfess.org. br/arquivos/CEP_1993.pdf >. Acesso em: 10 jan. 2018.

. Resolução CFESS n. 489, de 3 de junho de 2006. Estabelece normas vedando condutas discriminatórias ou preconceituosas, por orientação e expressão sexual por pessoas do mesmo sexo, no exercício profissional do assistente social, regulamentando princípio inscrito no Código de Ética Profissional. Disponível em: $<$ http://www.cfess. org.br /pdf/resolução_48920 06.pdf >. Acesso em: 10 jan. 2018.

. Resolução CFESS n. 594, de 21 de janeiro de 2011a. Altera o Código de Ética do Assistente Social, introduzindo aperfeiçoamentos formais, gramaticais e conceituais em seu texto e garantindo a linguagem de gênero. Disponível em: $<$ http://www. cfess. org.br/arquivos/Res594.pdf > . Acesso em: 10 jan. 2018. 
CONSELHO FEDERAL DE SERVIÇO SOCIAL. Resolução CFESS n. 615, de 8 de setembro de 2011b. Dispõe sobre a inclusão e uso do nome social da assistente social travesti e do(a) assistente social transexual nos documentos de identidade profissional. Disponível em: < http://www.cfess.org.br/ arquivos/615-11.pdf>. Acesso em: 10 jan. 2018.

. O amor fala todas as línguas. Assistente social na luta contra o preconceito: campanha pela livre orientação e expressão sexual CFESS Manifesta. 2007. Disponível em: $<$ http://www.cfess.org.br/arquivos/CFESSMANIFESTA-OAMORFALATODASAS LINGUAS.pdf>. Acesso em: 10 jan. 2018.

. Uma vida sem violência é um direito das mulheres: comprometa-se, tome uma atitude, exija seus direitos CFESS Manifesta. 2009. Disponível em: <http://www.cfess. org.br/arquivos/contraviolenciamulher2.pdf>. Acesso em: 10 jan. 2018.

. Denunciar é proteger. Sou assistente social. Eu denuncio! CFESS Manifesta. 2013. Disponível em: <http://www.cfess.org.br/visualizar/noticia/cod/962>. Acesso em: 16 jan. 2018.

. Assistentes sociais contra a violência e por direitos de pessoas LGBT. CFESS Manifesta. 2015. Disponível em: <http://www.cfess.org.br/js/library/pdfjs/web/viewer. html?pdf=/arquivos/2015-CfessManifesta-SeminarioTrans.pdf $>$. Acesso em: 16 jan. 2018.

. Série assistente social no combate ao preconceito: Transfobia. Caderno 4. 2016. Disponível em: <http://www.cfess.org.br/arquivos/CFESS-Caderno04-Transfobia-Site. pdf $>$. Acesso em: 15 jan. 2018.

. Assistentes sociais nos serviços de abortamento. CFESS Manifesta. 2017. Disponível em: <http://www.cfess.org.br/js/library/pdfjs/web/viewer.html?pdf=/ arquivos/2017-CfessManifesta-Aborto-SerieConjunturaeImpacto.pdf $>$. Acesso em: 16 jan. 2018.

MINISTÉRIO DA SAÚdE. SECRETARIA DE ATENÇÃO À SAÚDE. DEPARTAMENTO DE AÇÕES PROGRAMÁTICAS ESTRATÉGICAS. Atenção humanizada ao abortamento: norma técnica. Brasília: Ministério da Saúde, 2011. Disponível em: http://bvsms.saude.gov.br/bvs/publicacoes/atencao_humanizada_ abortamento_norma_tecnica_2ed.pdf. Acesso em: 17 mar. 2018.

NETTO, José Paulo. Ditadura e serviço social: uma análise do serviço social no Brasil pós-64. São Paulo: Cortez, 2011. 
PANEGHINI, Luciana Ribeiro. O Serviço Social e sua relação com o gênero feminino: anotações feministas socialistas sobre os primórdios da profissão até o início dos anos 80. In: XV ENCONTRO NACIONAL DE PESQUISADORAS(ES) EM SERVIÇO SOCIAL. Formação e trabalho profissional: reafirmando as diretrizes curriculares da Abepss. Anais, 4 a 9 de dezembro de 2016, Ribeirão Preto (SP). CD-ROM.

PINTO, Céli Regina Jardim. Uma história do feminismo no Brasil. São Paulo: Fundação Perseu Abramo, 2003.

TELES, Maria Amélia de Almeida. Breve história do feminismo no Brasil. São Paulo: Brasiliense, 1999. 